\title{
EVALUATION OF DYNATRAP® DT160 AS AN INEXPENSIVE ALTERNATIVE TO CDC TRAPS FOR ADULT MOSQUITO MONITORING IN MALI, WEST AFRICA
}

\author{
MOHAMED M. TRAORE', AMY JUNNILA', JEROME A. HOGSETTE', \\ DANIEL L. KLINE ${ }^{2}$, KAREN MCKENZIE ${ }^{3}$, VASILIY KRAVCHENKO ${ }^{1,4}$, \\ ABOUBAKR S. KONE', RABIATOU A. DIARRA', SEKOU F. TRAORE', \\ GERGELY PETRANYI', PENDA SANGARE', ASSITAN DIAKITE', \\ ISSA TROARE', JOHN C. BEIER ${ }^{5}$, EDITA E. REVAY', RUI-DE XUE ${ }^{6}$, \\ AND GUNTER C. MULLER' \\ 'Malaria Research and Training Centre, Faculty of Medicine, \\ Pharmacy and Odonto-Stomatology, University of Sciences, \\ Techniques and Technology of Bamako, BP 1805 Bamako, Mali
}

${ }^{2}$ USDA-ARS, Center for Medical, Agricultural and Veterinary Entomology, 1600 S.W. 23 ${ }^{\text {rd }}$ Drive, Gainesville, FL, 32608, USA

\begin{abstract}
${ }^{3}$ Woodstream Corp., 2226 Sarno Rd Ste 104, Melbourne FL, 32935, USA
${ }^{4}$ The Steinhardt Museum of Natural History, Israel National Center for Biodiversity Studies and Department of Zoology Tel Aviv University, Tel Aviv, 6997801, Israel
\end{abstract}

${ }^{5}$ Department of Public Health Sciences, Miller School of Medicine, University of Miami, Miami, FL, 33136, USA

${ }^{6}$ Anastasia Mosquito Control District, 120 EOC, St. Augustine, FL 32092, USA

Guest Editor: Christopher S. Bibbs

\begin{abstract}
Mosquito monitoring traps (i.e., CDC light traps) are crucial tools for basic vector ecology research, risk assessment, and vector control programs. Unfortunately, they are expensive which is often an issue in projects conducted in developing countries. Therefore, it would be desirable to have reliable but inexpensive alternatives based on existing consumer products. We compared an off-the-shelf DynaTrap (model DT160, CCFL tube $365 \pm 3 \mathrm{~nm} \mathrm{UV)}$ modified to fit a CDC trap collection bag and to use a $12 \mathrm{~V}$ power supply, with two commonly used CDC traps: CDC Miniature Light Trap Model 512 (incandescent light, 6 Volt) and CDC Miniature Downdraft Blacklight (UV) Trap Model 912 (4-Watt blue-black-light tube, 12 Volt), in different ecological settings in southwest (Kenieroba) and northwest (Nioro du Sahel) Mali, West Africa. In northwest Mali, the modified DynaTrap caught a mean of 20.67 \pm 2.8 females and $5.38 \pm 1.0$ male Aedes aegypti which was $16.55 \%$ and $10.78 \%$ more, respectively, than the CDC incandescent trap (control). The DynaTrap caught a mean of $29.75 \pm 2.8$ female and $17.92 \pm 3.5$ male Culex quinquefasciatus. which was $47.76 \%$ and $20.70 \%$ more than the control CDC incandescent trap. The DynaTrap caught a mean of $2.46 \pm 0.5$ females and $1.63 \pm 0.6$ males and $10.16 \%$ and $2.45 \%$ more female and male An. gambiae s.l., respectively, than the CDC incandescent trap. Trap and catch means were lower at the southwest Mali site. However, trap catch proportions by sex were similar to those in the northwest. The modified DynaTrap outperformed both CDC monitoring traps for less than one third of the cost including the cost of the DynaTrap modifications.
\end{abstract}

Key Words: Surveillance traps, trap costs, Aedes aegypti, Anopheles gambiae s.l., Culex quinquefasciatus, Mali 


\section{INTRODUCTION}

Mosquito surveillance is a critical component of mosquito and vector management operations around the world providing important information on the population dynamics of target species present in a specific geographic area, especially those of medical, veterinary, and public health importance (Kline et al. 2006). Dacko et al. (2020) define mosquito surveillance as a systematic, rigorous, and continued effort to monitor mosquito populations over time to obtain information about distribution, abundance, and species composition. These data are used to assess the risk of mosquito-borne pathogens that cause disease outbreaks and the need for or efficacy of intervention efforts. Silver (2008) reviews the available tools to conduct this surveillance. Mosquito light traps are one of the most common tools used. In the United States, the Centers for Disease Control and Prevention (CDC) miniature light trap has been the standard light trap (Sudia and Chamberlain 1962) used by mosquito abatement districts for decades because it is portable, easy to set up, and captures a wide variety of mosquitoes. However, the expense can become prohibitive to wider scale experiments. When choosing an appropriate trap for use in developing nations one must consider cost of mosquito surveillance operations as well as trap efficacy and portability. Thus, improved surveillance strategies in these developing countries should demonstrate high levels of efficacy, field robustness, affordability, and scalability.

Vector surveillance traps are an essential tool for mosquito and vector control operations around the world. Ovitraps and gravid traps, as well as adult traps, are used to get a complete picture of the species that are found in each area (Service 1993). Adult traps typically attract mosquitoes with light or a combination of light and carbon dioxide (Kline 1994). The standard, lightweight and easy to deploy, CDC incandescent light trap has not evolved much since it's development from the late 1950s to the early 1960s by Dan Sudia, Roy Chamberlain and the CDC Equipment Development Shop (CDC,
2015). What has changed over time is the cost of these traps. Current costs in the United States for a standard CDC incandescent light trap is approximately $\$ 100$ USD, plus the cost of a collection net. If an ultraviolet (UV) light source is preferred, the cost of the traps is closer to $\$ 200 \mathrm{USD}$. These prices are reasonable if only a few traps are required for a project. However, with many surveillance projects and/or control programs, many surveillance traps are needed. These costs, in bulk, can become an extreme burden on program budgets. For these reasons, we examined a lower cost UV light trap, the DynaTrap DT160, that was developed as a budget retail-use trap for consumers that could be modified easily by the manufacturer to connect to a 12-v battery. We evaluated the DynaTrap with the CDC-incandescent (model 512) and the CDC-UV (model 912) traps to determine the comparative efficacy for catching 3 commonly encountered genera of mosquitoes (Aedes, Anopheles and $\mathrm{Cu}$ lex) in Mali. Approximately three DynaTrap consumer traps can be purchased for the cost of one CDC-UV light trap.

\section{MATERIALS AND METHODS}

Study sites. The two sites in Mali, West Africa, chosen to study the modified DynaTrap, were Nioro du Sahel, NW Mali $\left(-9.60475788800^{\circ} \mathrm{N}, 15.22491160900^{\circ} \mathrm{W}\right)$ and Kenieroba, SW Mali (-8.32928630400 ${ }^{\circ} \mathrm{N}$, $\left.12.11465570600^{\circ} \mathrm{W}\right)$. At each site, two traps of each kind were operated over 12 consecutive nights (or day/night). Traps were rotated daily to avoid positional bias. The trials were conducted twice resulting in a total of 24 trapping days per tested trap.

Traps. The traps compared in this study were: the DynaTrap model DT160, light source: CCFL tube $365 \pm 3$ nm UV (Woodstream Corp., Melbourne FL, USA), the CDC incandescent model 512, light source: light bulb, incandescent (John W. Hock, Gainesville FL, USA), and the CDC-UV Trap model 912, light source: UV 4-Watt blue-black-light tube, 12 Volt (John W. Hock, Gainesville FL, USA). Typically, for consumer use, the DT160 comes equipped with the standard 
$120 \mathrm{~V}$ AC to $12 \mathrm{~V}$ DC power adapter. For testing purposes, the $120 \mathrm{~V}$ power adapter was replaced with battery clips to allow the DynaTrap to directly connect to a $12 \mathrm{~V}$ battery source, as shown (Fig. 1a).

To increase the capacity of the DynaTrap catch container, the floor of the trap collection basket was removed, and the opening was fitted with a large $(44 \mathrm{~cm}$ length $\mathrm{x} 35$ $\mathrm{cm}$ lower diameter) net catch bag modified from the John Hock model 512 collection net (part number 1.42). All traps were suspended 1.5-m above the ground, either on tripods or other suitable constructions, outdoors in direct proximity to houses (Fig. 1b), with a distance of $25 \mathrm{~m}$ (minimum) between them. Traps were designed or modified for use with 12-v, 10-amp batteries and were spaced at least 30-m apart. After each overnight trapping period, batteries were changed, and traps were rotated sequentially between the three trap locations at each trapping site.

Mosquito species. The two nuisance mosquitoes, Culex quinquefasciatus and Aedes aegypti are invasive species and are distributed almost globally. In the USA, both species are common from early summer to autumn, while in Mali, West Africa, the same species

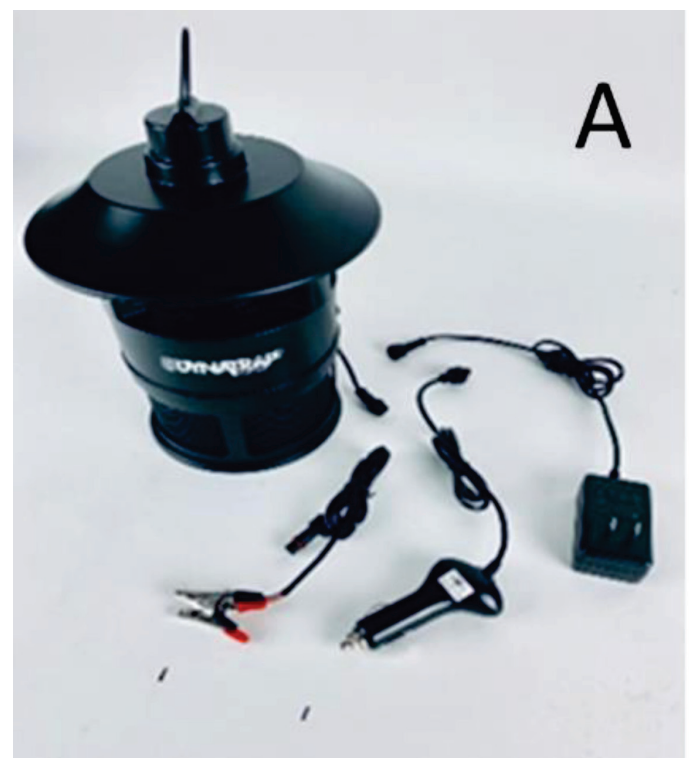

Figure 1. a) DynaTrap DT160 showing battery clips and power cord. b) DynaTrap DT160 showing modified collection net and power supply.

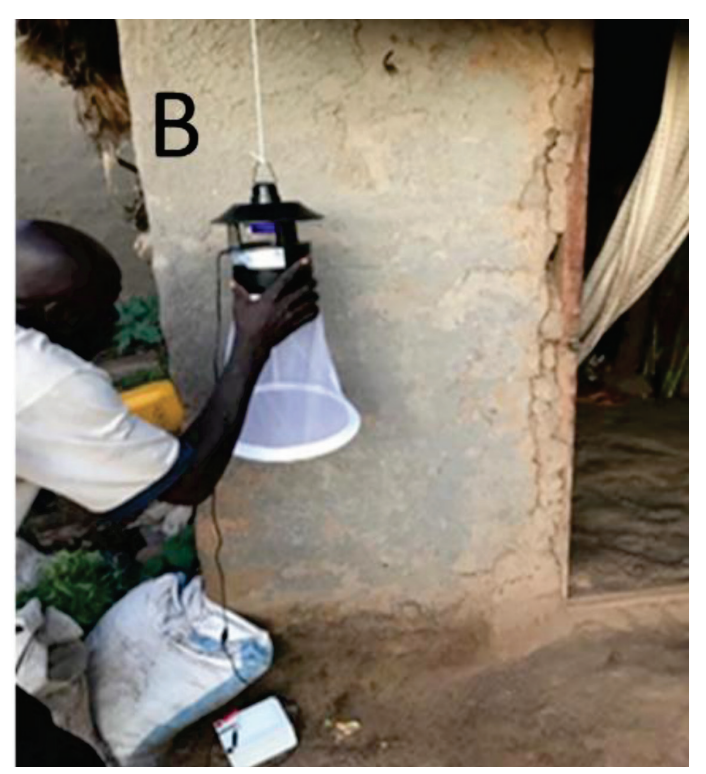

are abundant year-round. The trials conducted in West Africa were done in a similar environment as found in the southern USA. Anopheles gambiae s.l., an important malaria vector in Africa, is a representative of the genus. Others can also be found in the United States: An. quadrimaculatus (Eastern USA) and An. freeborni (Western USA).

Statistics. The numbers of mosquitoes caught within each site (male and female) were analyzed using two-way ANOVA followed by a Tukey's post-hoc test to rank significance levels. Differences were said to be significant at $\mathrm{P}<0.05$. Analysis was conducted using GraphPad Prism 8.00 for windows (GraphPad Software, La Jolla California, USA). The difference between the mean number of mosquitoes $( \pm$ SEM), and $P$-values of the comparisons are reported in the tables 1-3.

\section{RESULTS}

As expected, all traps caught significantly more females than males regardless of site. Figures 2, 3 and 4 show the mean daily/nightly catches of mosquitoes at the two trapping sites in Mali: Nioro du Sahel and Kenieroba. In general, the DynaTrap and 


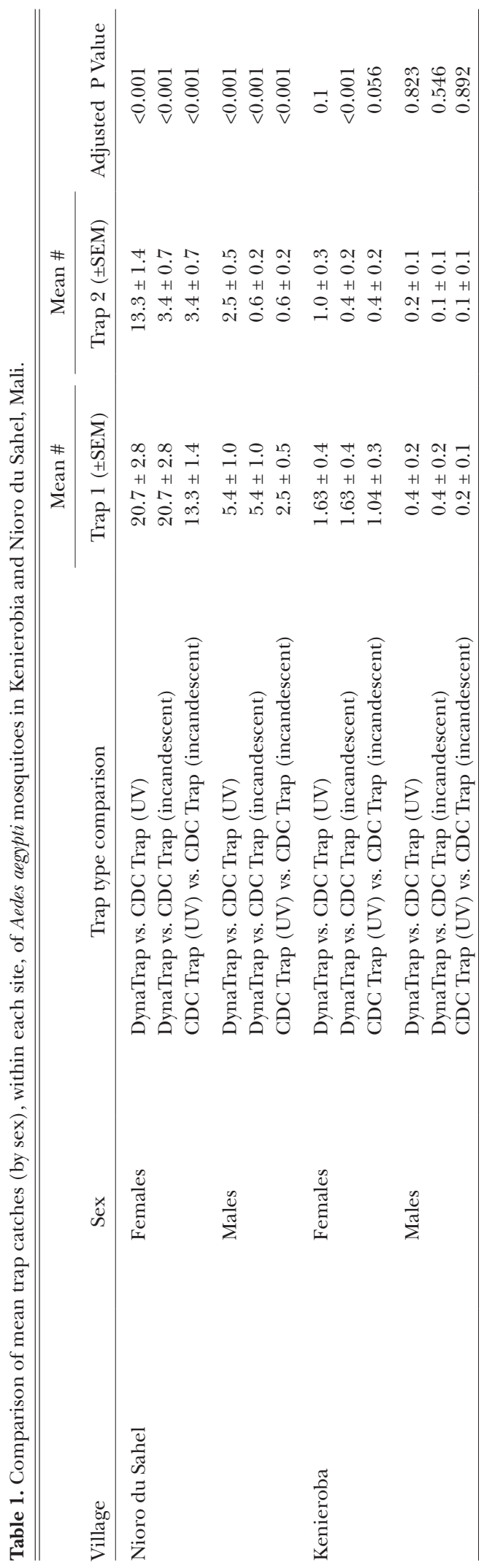




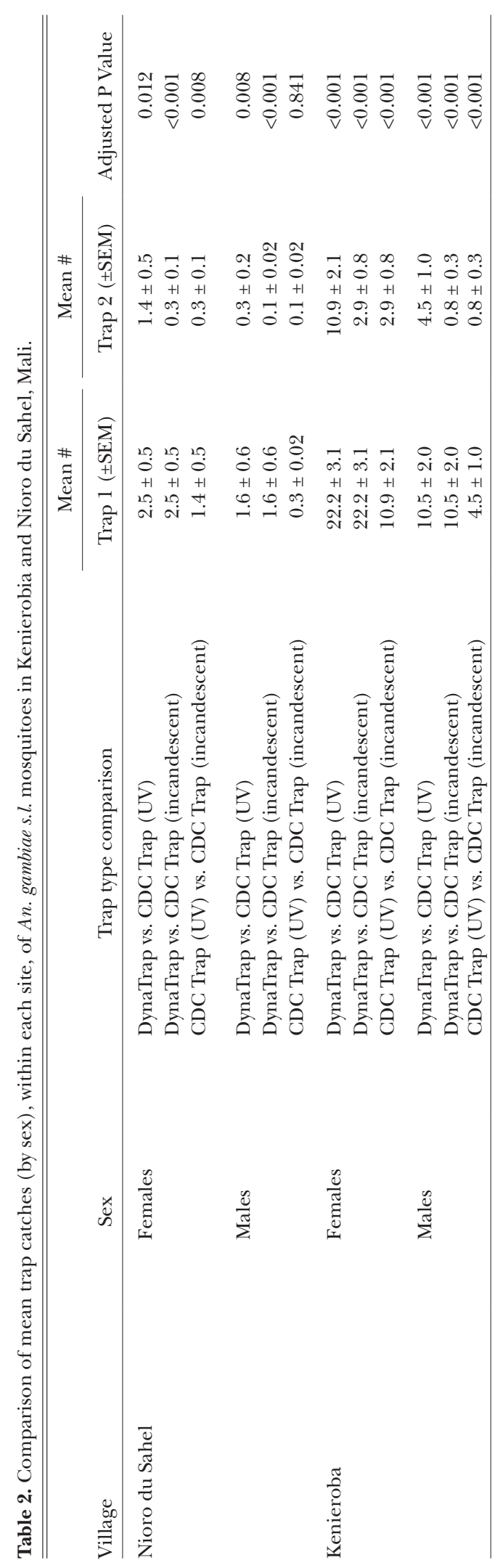




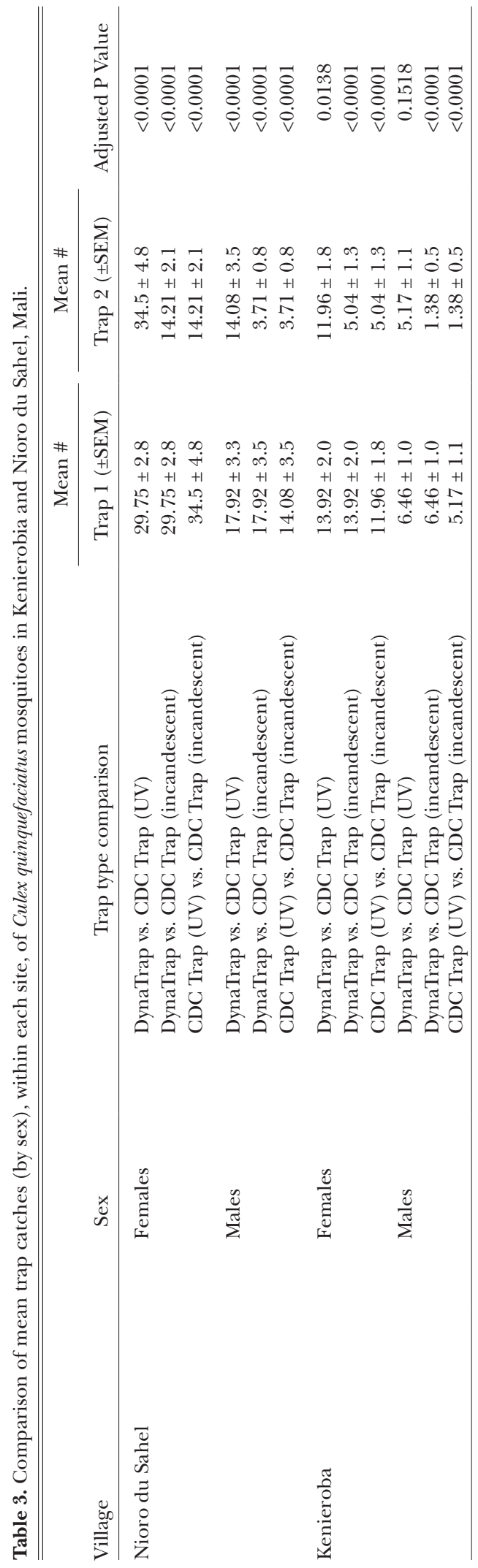


Male and Female Aedes aegypti caught at sites in Mali

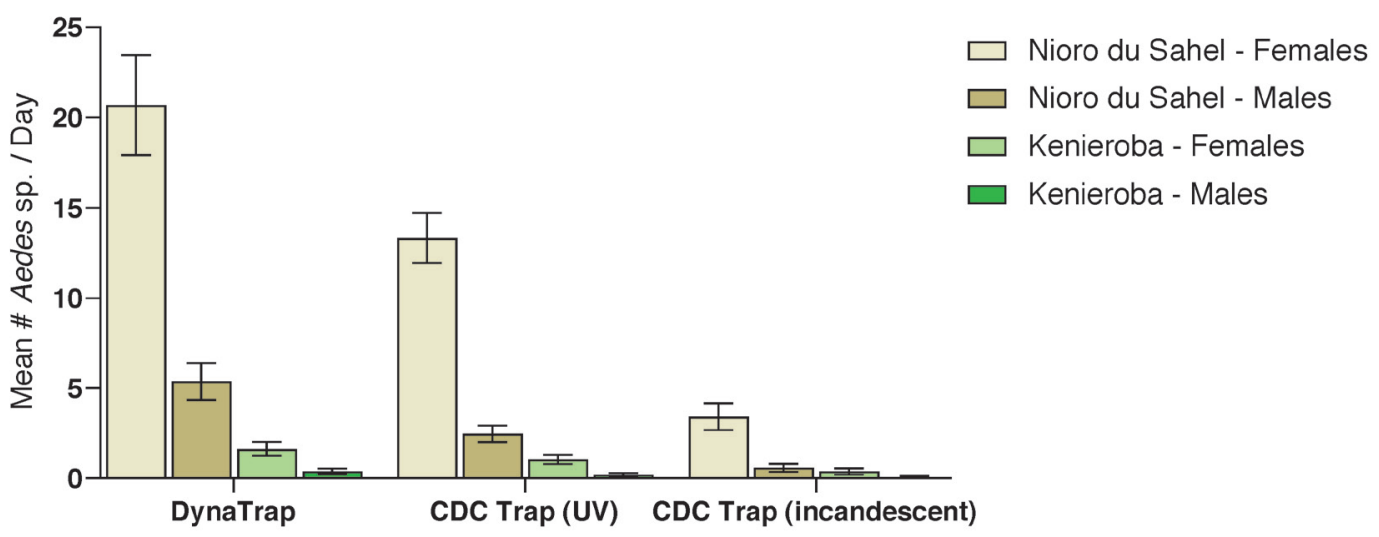

Trap Type

Figure 2. Average catch of male and female Aedes aegypti. mosquitoes per day/night \pm SEM at the two trapping sites in Mali.

CDC-UV traps caught more mosquitoes than the CDC incandescent trap. In Nioro du Sahel the CDC-UV trap captured more $C x$. quinquefasciatus females than the modified DynaTrap (Fig. 4). All of the traps caught very few males.

\section{DISCUSSION}

The World Health Organization has emphasized the need to strengthen and integrate surveillance into a major core com- ponent of strategies to combat mosquitoborne diseases (WHO 2017, 2019a). For this to happen, affected countries require inexpensive, scalable tools for monitoring, plus a set of simplified surveillance indicators. Smith et al. (2007) and WHO (2019b) have indicated that surveillance for malaria and other vector-bone diseases plays a major role in: tracking transmission; assessing susceptibility of vectors to interventions; measuring receptivity in specific locations; and predicting disease outbreaks. A number of traps are

Male and Female Anopheles gambiae s.l. caught at sites in Mali

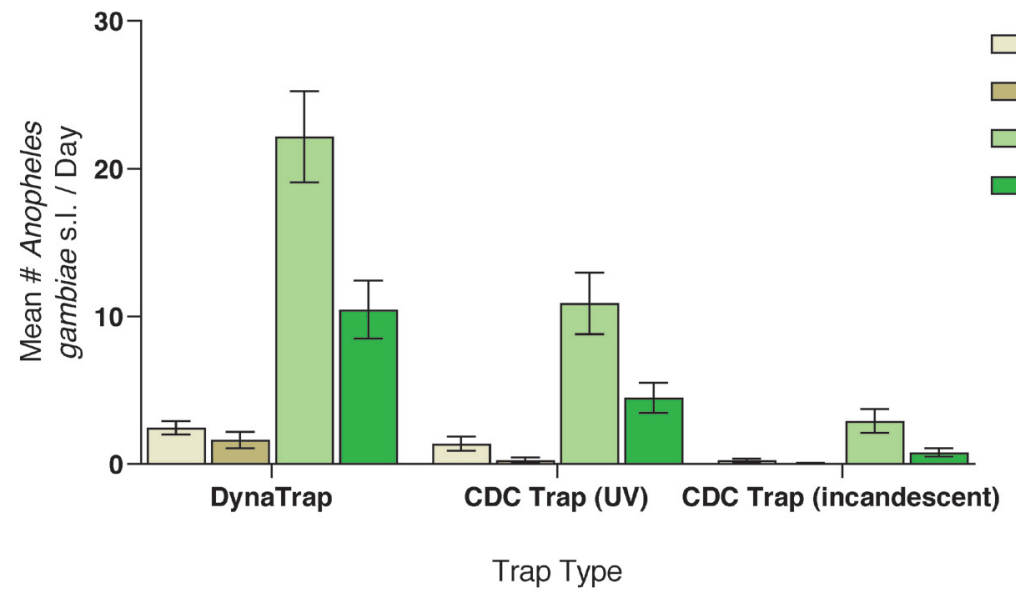

Figure 3. Average catch of male and female Anopheles gambiae s.l. mosquitoes per day/night \pm SEM at the two trapping sites in Mali. 


\section{Male and Female Culex quinquefasciatus caught at sites in Mali}

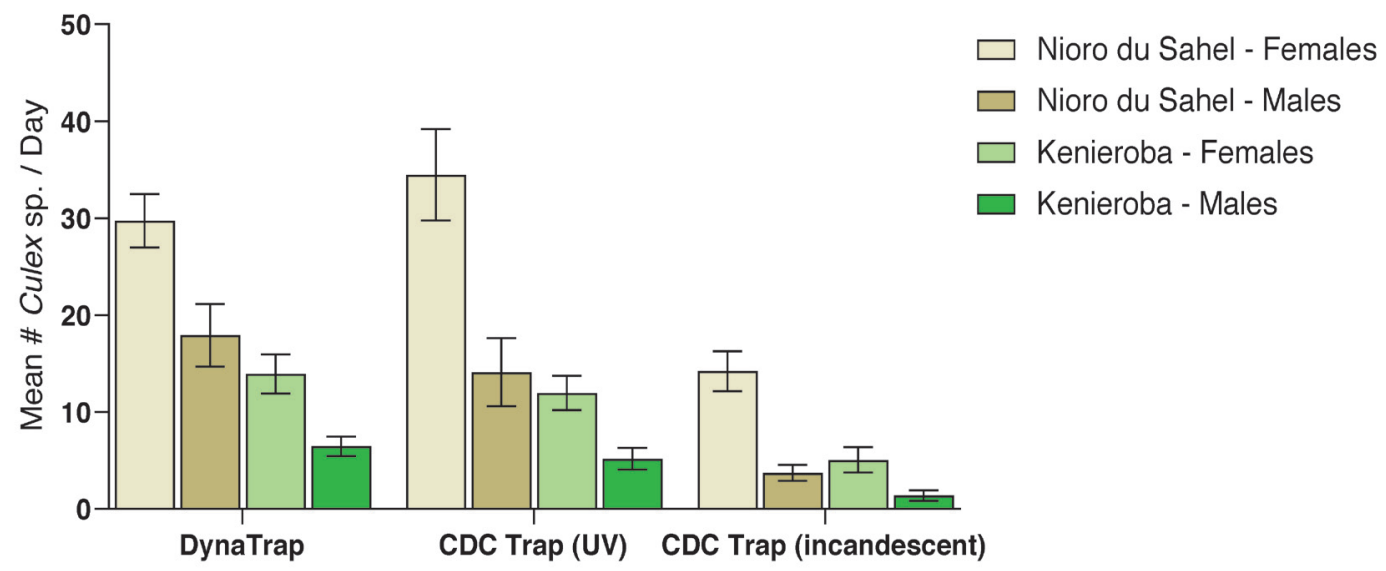

Trap Type

Figure 4. Average catch of male and female Cx. quinquefasciatus mosquitoes per day/night \pm SEM at the two trapping sites in Mali.

In both ecological settings, the modified DynaTrap caught numerically but not always significantly more mosquitoes overall than the CDC incandescent trap and the CDC-UV trap. Only in Nioro du Sahel (in the case of female $C x$. quinquefasciatus quinquefaciatus) did the CDC-UV trap catch significantly more females than the modified DynaTrap (Table 2).

on the market that have been included in operational mosquito sampling and surveillance programs (Mboera 2006, Davis et al 1995, Silver and Service 2008). Some traps have been found to be efficacious enough to be intervention devices in mosquito control systems (Rapley et al. 2009, Day and Sjogren 1994, Okumu et al. 2010). A major and commonly seen problem with many traps is poor scalability, most often because of their physical structure and relatively high cost.

The Center for Disease Prevention and Control light trap (CDC-light trap), improved by Sudia \& Chamberlain (1962) by adding an incandescent light, is widely used for indoor collections of host-seeking mosquitoes (Mboera et al. 1998, Zaim and Ershadi 1986). The CDC-light trap uses light bulbs (incandescent and later, UV), battery cells, and a motor-driven fan, all of which make it expensive and difficult to maintain in many settings. Despite these challenges, the CDC-light trap is still considered one of the simplest trapping techniques, requiring only light as an attractant.

To improve surveillance strategies against vector-borne infections, new trap- ping devices are required that demonstrate high levels of efficacy, field robustness, affordability, and scalability. Mwanga et al. (2019) evaluated the efficacy of a new ultraviolet LED trap (Mosclean) against standard CDC incandescent light in rural south-eastern Tanzania. When simultaneously placed inside the same semi-field chamber, the Mosclean trap caught twice as many Anopheles arabiensis as the CDC-light trap. These traps also caught equal numbers of An. arabiensis and twice as many $C x$. quinquefasciatus mosquitoes as CDC-light traps in the field. The Mosclean trap emits optimized high efficiency UV LEDs (wavelength of $365 \mathrm{~nm}$ ) to attract mosquitoes. An additional advantage is that the lamp can run for more than 10,000 hours and therefore requires less frequent replacements than the incandescent lamps that, used in the CDC-light trap, typically run for 1200 hours or less (Viribright 2019).

In the current study, the light source of the tested trap (DynaTrap DT160) was a Cold Cathode Fluorescent Light (CCFL) tube. The trap was compared to the "goldstandard" CDC-light traps with incandes- 
cent and UV light bulbs, which are commonly used for trapping mosquitoes inside and outside of human dwellings. The DynaTrap DT160 $3.5 \pm 10$ W CCFL light source produces a wavelength of $365 \pm 5 \mathrm{~nm}$, drawing $0.4 \mathrm{~A} /$ hour from a $12 \mathrm{~V}$ battery. In comparison, per the manufacturer's website (John Hock 2019), the Model 912, CDC style, downdraft blacklight trap uses a "4-Watt blue-blacklight tube and a very efficient transistorized inverter-ballast to provide radiation in the near-UV range (ca. 320-420 nm)". The Model 912 draws 0.5A/ hour from a $12 \mathrm{~V}$ battery. While very similar in output, better performance of the DynaTrap could be explained by the differences in the type of UV source, the narrower range of the UV spectrum, as well as the configuration of the bulb.

It is worth noting the differences in the trap catch of each species based on the site it originated from. Kenieroba, in SW Mali, has much higher levels of An. gambiae s.l. owing to its wetter climate and concentrated presence of human beings. Nioro du Sahel, in NW Mali, is located in an arid semidesert has more suitable habitat for Aedes aegypti and Cx. quinquefasciatus. Although each trap type reflected this, the DynaTrap caught the most females of all species which is the goal from a disease surveillance perspective.

This study demonstrates that it is feasible to outfit commercial mosquito traps to suit the needs of field researchers which continue to be scalability, robustness, cost, and efficacy. With minimal and simple modifications, the DynaTrap DT160 was effective under field conditions where electricity may not be readily available and did so in a costeffective manner. It also caught similar numbers of female mosquitoes of all three species evaluated and can, therefore, be used in place of the more costly CDC light traps for monitoring adult mosquitoes in the field. The DynaTrap also caught An. gambiae s.l. females in comparable numbers to the CDCUV trap and can thus be good candidates for surveillance in between traps and West Africa. Future work should focus on testing this hypothesis in other regions of Africa towards a broader range of species of medical importance, a limitation of the current study.

\section{ACKNOWLEDGEMENTS}

The authors wish to thank communities in Bamako and Kenieroba, Mali that participated in the study. The trials were in part supported by the ICEMR Vector supplement Grant Number 5U19AI089672.

\section{REFERENCES CITED}

CDC. Mosquito Light Trap. 2015 https://www.cdc.gov/ museum/history/mosquito.html. Accessed 18 Oct 2020.

Dacko NM, MR Nava, C Vitek, M Debboun. 2020. Chapter 7, pp 221-247, Mosquito surveillance, In M Debboun, MR Nava. LM Rueda (eds). Mosquitoes, Communities and Public Health in Texas, Academic Press (Elsevier).

Davis JR, Hall T, Chee EM, Majala A, Minjas J, Shif CJ. 1995. Comparison of sampling Anopheline mosquitoes by light-trap and human-bait collections indoors at Bagamoyo, Tanzania. Med Vet Entomol 9:249-255.

Day JF, Sjogren RD. 1994. Vector control by removal trapping. Am J Trop Med Hyg. 50:126.

John W. Hock. 2019. CDC Miniature Light Trap. https://johnwhock.com/ products/mosquito-sandfly-traps/cdc-miniature-light-trap/. Accessed 5 Feb 2019.

Kline DL, M Patnaude, DR Barnard. 2006. Efficacy of four trap types for detecting and monitoring $\mathrm{Cu}$ lex spp. in north central Florida. J Med Entomol. 43: 1121-1128.

Mwanga EP, Ngowo HS, Mapua SA, Mmbando AS, Kaindoa EW, Kifungo K, Okumu FO. 2019. Evaluation of an ultraviolet LED trap for catching Anopheles and Culex mosquitoes in south-eastern Tanzania. Parasites Vectors 12:418 https://doi.org/10.1186/s13071019-3673-7

Mboera LEG. 2006. Sampling techniques for adult Afrotropical malaria vectors and their reliability in the estimation of entomological inoculation rate. Tanzan J Health Res. 7:117-124

Mboera LEG, Kihonda J, Braks MA, Knols BG. 1998. Short report: Influence of centers for disease control light trap position, relative to a human baited bed net, on catches of Anopheles gambiae and Culex quinquefasciatus in Tanzania. Am J Trop Med Hyg. 59:595-596.

Okumu FO, Govella NJ, Moore SJ, Chitnis N, Killeen GF. 2010. Potential benefits, limitations and target product-profiles of odor-baited mosquito traps for malaria control in Africa. PLoS One. 2010;5:e11573

Rapley LP, Johnson PH, Williams CR, Silcock RM, Larkman M, Long SA, et al. 2009. A lethal ovitrap-based mass trapping scheme for dengue control in Australia: II. Impact on populations of the mosquito Aedes aegypti. Med Vet Entomol. 23:303-316.

Service MW. 1993. Mosquito ecology: field sampling methods. London: Elsevier Applied Science.

Silver JB, Service MW. 2008. Mosquito ecology: Field sampling methods. London: Springer. 
Smith DL, McKenzie FE, Snow RW, Hay SI. 2007. Revisiting the basic reproductive number for malaria and its implications for malaria control. PLoS Biol. 5:e42.

Sudia WD, Chamberlain RW. 1962. Battery-operated light trap, an improved model. Mosq News. 22:126-129.

Viribright. 2019. Comparing LED vs CFL vs incandescent light bulbs. https://www.viribright.com/ lumen-output-comparing-led-vs-cf-vsincandescentwattage/. Accessed $10 \mathrm{Feb} 2019$.

World Health Organization (WHO). 2018. Malaria surveillance, monitoring \& evaluation: a reference manual. http://www.who.int/malaria/publications/ atoz/9789241565578/ en/. Accessed 5 Feb 2019.

WHO. 2015. Global technical strategy for malaria 2016-2030. http://apps. who.int/iris/bitst ream/10665/176712/1/9789241564991_eng. pdf?ua=1. Accessed 2 Feb 2019.

WHO. 2017. Global vector control response 2017-2030. Geneva: World Health Organization; 2017.

Zaim M, Ershadi MR, Manouchehri AV, Hamdi MR. 1986. The use of CDC light traps and other procedures for sampling malaria vectors in southern Iran. J Am Mosq Control Assoc. 2:511-515. 